\begin{tabular}{|c|c|c|}
\hline $\begin{array}{l}\text { PKS } \\
\text { PUBLIC } \\
\text { KNOWLEDGE } \\
\text { PROJJECT }\end{array}$ & $\begin{array}{c}\text { REVISTA DE GEOGRAFIA } \\
\text { (UFPE) } \\
\text { www.ufpe.br/revistageografia }\end{array}$ & $\begin{array}{l}\text { OJS } \\
\text { OPEN } \\
\text { JOUNAL } \\
\text { SYSTEMS }\end{array}$ \\
\hline
\end{tabular}

\title{
POR UM DIÁLOGO SOBRE O PAPEL E O USO DAS TICS NA FORMAÇÃO DOS PROFESSORES DE GEOGRAFIA: fios soltos e possibilidades de uni-los
}

\author{
Lucas Antônio Viana Botêlho', Francisco Kennedy Silva dos Santos ${ }^{2}$ \\ 1 Doutorando em Geografia. Mestre em Geografia. Licenciado em Geografia. Todos os cursos pela \\ Universidade Federal de Pernambuco. Professor substituto do curso de Licenciatura em Geografia da \\ UFPE. Colaborador no Grupo de Pesquisa Educação, Cultura Escolar e Inovação. (GPECI/UFPE/CNPq), \\ Email: lucasviana.botelho@gmail.com \\ 2 Professor e pesquisador do Programa de Pós-Graduação em Geografia da UFPE. Líder do Grupo de \\ Pesquisa Educação Geográfica, Cultura Escolar e Inovação (GPECI/UFPE/CNPq), Email: \\ kennedyufpe@gmail.com
}

\begin{abstract}
RESUMO: No cenário atual, verifica-se a necessidade de pensar estrategicamente a inserção das tecnologias da informação e comunicação como possibilidade de formação de professores situada num campo de abertura aos processos de releitura e reinvenção das práticas. No entanto, igualmente pode-se constatar que há improvisos, gerado estes impasses quanto ao trato da questão, acarretando um mal atendimento e entendimento das demandas emergentes no chão da escola. Propõe-se um uso utilitarista e instrumental destes meios, ao invés de toma-los como possibilidade de ação criativa e participativa. $\mathrm{O}$ presente trabalho objetiva discutir impasses, improvisos e possibilidades quanto ao uso e ao papel das TICs na formação e na prática cotidiana dos professores de Geografia. Faz-se um levantamento de referências que possam construir uma leitura e análise crítico-reflexiva do tema, mergulhando na seara de questões que permeiam o debate e formulando possíveis proposições a se pensa-las e questiona-las a partir de problematizações outras.
\end{abstract}

Palavras-chave: TICs, formação de professores, processos formativos, prática reflexiva.

\section{FOR A DIALOGUE ON THE ROLE AND USE OF ICTS IN THE TRAINING OF TEACHERS OF GEOGRAPHY: loose threads and possibilities of uniting them}

\begin{abstract}
In the current scenario, there is a need to think strategically the insertion of information and communication technologies as a possible training of teachers in the field of openness to reinterpretation and reinvention of traditional named. However, also you can see that there are improvisations, generated these impasses regarding dealing with the issue, causing an evil care and understanding of emerging demands on the floor of the school. It is proposed that a utilitarian use and instrumental of these means, instead of taking them as a possibility of creative action and participatory. This paper aims to discuss impasses, improvisations and possibilities regarding the use and role of ICTs in the training and daily practice of Geography teachers. There is a survey of references that can construct a critical-reflective reading and analysis of the theme, delving into the range of questions that permeate the debate and formulating possible propositions to think about them and question them from other problematizations.
\end{abstract}

Keywords: ICT, teacher training, formative processes, reflective practice. 


\section{INTRODUÇÃO}

Há muito o que ser refletido-dito-experienciado, quando o que está colocado em uma pauta problematizadora é a formação de professores. O debate que compreende este campo de pesquisa é bastante amplo e incorpora elementos que estão associados a diversas perspectivas e tendências. No entanto, é preciso ponderar que estas múltiplas lentes, utilizadas para averiguar a temática, convergem num único sentido: é preciso repensar os processos formadores de docentes.

Deste modo, é conveniente que a discussão proposta neste texto mergulhe na seara de elementos que estão associados a profundidade dos debates que originam, desenvolvem e concluem quais necessidades tornam-se emergentes na formação docente contemporânea. As tecnologias de informação e comunicação, ou TICs, são elementos propostos como eixo que atravessa e se materializa em todas as temáticas que perpassam a formação e a prática profissional dos professores. Daí a necessidade de pensar sobre o tema e apurar quais caminhos são possíveis e quais possibilidades emergem no chão da formação.

Neste cenário de imersão nas TICs, verifica-se uma sucessão de improvisos e de incertezas, provocados pela atribuição utilitarista e instrumental destes meios, tanto na formação quanto na experiência cotidiana do professor. Daí decorre, então, impasses que tornam-se a "pedra de tropeço" para muitos destes profissionais que, ao egressar dos cursos de formação incial e chegar a sala de aula, reproduzem mecanicamente o uso destes meios, de acordo com o limitiro repertório de memórias pedagógicas obtidas ao longo de sua formação inicial.

Por outro lado, verifica-se que a continuidade da formação, quer seja nos espaços e momentos propícios para cursos de aperfeiçoamento da formação inicial quer seja no cotidiano pedagógico em que está imerso este sujeito, não dá conta de uma reelaboração e apropriação consciente e coerente com as demandas que emergem no planejamento e na reflexão sobre a prática. Aliás, onde está o espaço para reflexão sobre a prática?

Que visão se tem dos processos formativos e que atribuições as tecnologias desempenham nestes? Que aspectos e fatores alimentam os usos das TICs na formação e na prática dos professores de Geografia? Que possíveis caminhos podem ser trilhados por estes profissionais, desvirtuando a lógica do consumo inconsciente e inconsistente destes meios? O presente texto intenta discutir impasses, improvisos e possibilidades quanto ao uso e ao papel das TICs na formação e na prática cotidiana dos professores de Geografia. 
Para tanto, faz-se um levantamento de referências que possam construir uma leitura e análise crítico-reflexiva do tema, mergulhando na seara de questões que permeiam o debate e formulando possíveis proposições a se pensa-las e questiona-las a partir de problematizações outras.

\section{OS CAMINHOS DA FORMAÇÃO DE PROFESSORES EM GEOGRAFIA: FIOS SOLTOS}

Desde que institucionalizada, a formação de geógrafos, sobretudo aqueles a que se atribui uma dimensão pedagógica, de acordo com Pereira (1999), passou por movimentos de mudança que buscavam situar o campo de formação e atuação em níveis de complexidade e equivalência com as demandas socioeducacionais crescentes. Assim como em todas as áreas compreendidas pelas ciências humanas e sociais, as mudanças foram paulatinamente colocando em "xeque" a ausência de um teor crítico e reflexivo, o qual permitiria a reconstrução dos roteiros que alienavam os professores de sua práticas. Como aborda Silva (2011, p. 34), a descoisificação do professor, acarretada pela alienação a que este esteve submetida durante longos anos, tornou-se possível graças a "busca de uma nova pedagogia".

$\mathrm{O}$ atravessar das fronteiras que trincheiravam tendências tradicionais de um olhar crítico-social não se deu de forma completa. Persiste-se ainda em práticas cujo teor é a transmissividade e a transposição didática dos conhecimentos, onde, muitas vezes, não há espaço suficiente para pensar o “o que?”, “o porquê?” e o “como fazer?”. Até o presente momento, verifica-se que a criação de uma agenda, cuja pauta maior seja a abertura de espaços mais amplos ao teor crítico-reflexivo, ou seja, o pensar-dialogar-agir, não conseguiu tornar-se uma plenitude e um totalidade entre educadores e pesquisadores.

Nos tempos hoje vivenciados, é perceptível que há ainda tensões neste campo, sobretudo provocadas pelo adentramento de pespectivas que dão um passo maior ainda, questionando a crítica pela crítica e a reflexão pela reflexão. A busca pelo sentido e pelo nexo, que tende a desvirtuar uma educação clichê (FERRAÇO, 2015), tem sido a frequente bandeira da militância pedagógica, tanto por parte dos pesquisadores em educação quanto por parte dos sujeitos que tecem os fios dos processos de aprendizagem em acontecimento cotidiano na escola. Aponta-se, neste caso, para uma reflexão situada, uma reflexão na ação (SCHÖN, 1997). 
Os apontamentos que devem e precisam ser feitos, no que diz respeito ao processo de formação de professores em Geografia, vai muito além das especificidades, dilemas e imbricações da disciplina em tela, pois pertence a um campo macro, ao campo da feitura e execução das políticas educacionais. E é a partir destas que se deve pensar os processos de desvalorização da docência, desde a formação até as intempéries da sala de aula (LOPES, 2006).

A partir disto, é conveniente que se faça alusão também a crescente demanda neoliberalista por profissionais altamente inventivos e criativos, dotados de um notório saber, o qual nem sempre está atrelado a uma formação inicial ocorrente no âmbito de uma licenciatura em específico, como é o caso da Geografia. Levando a uma precarização da profissão, que mais parace um ofício sem saberes (GAUTHIER et al, 1998).

Mais claramente, o conjunto de instabilidades no campo da teoria e multiplicidades no campo das metodologias, a partir e nas práticas formativas de professores, geram uma série de cenários divergentes. Ora é possível encontrar instituições nas quais há avanços significativos, demonstrando o fortalecimento de um debate acerca da formação e uma preocupação com a materialidade dos elementos presentes nestes debates, ora encontra-se instituições incapazes de avançar e de dar conta da complexidade do tecido social destes tempos, gerando os impasses e improvisos e, porque não dizer, descaminhos da formação docente (LEITE, 2011).

Os cursos de licenciatura em Geografia apresentam dissonâncias, descompassos, impasses, como apuram pesquisas na área. O improviso é a marca da formação de professores no Brasil, não há como negar. As políticas educacionais tendem a olhar para frente, propondo possíveis avanços, a partir de um cenário presente, mas os pés permanecem no passado, como analisa David (2015). Desta forma, a legislação cria as incertezas, as quais nem todas as instituições conseguem driblar, devido a uma série de fatores, dentre os quais deve-se destacar a ausência de recursos financeiros necessários para tal feito.

Resultado da lógica neoliberal, conforme Girotto (2017), geradora do que aqui nomeamos "fios soltos". A presença visceral da lógica neoliberalista, como mediadora das políticas educacionais, não é exclusividade do Brasil, porém é bem verdade que o processo de redemocratização não garantiu uma retomada forte, mesmo diante da efervescência da pesquisa educacional (ALARCÃO, 2001), de um diálogo entre sociedade, universidade e escola. 
O professor é formado para um cenário que desconhece, tanto em teoria quanto em prática, tendo em vista que os estágios supervisionados, e outros componentes curriculares que compõem os perfs curriculares dos cursos Brasil afora, ainda não conseguem dar conta suficientemente da construção do perfil profissional, mobilizando os saberes necessários para tal, incorrendo na liberação de profissionais ainda sem preparação suficiente para das especificidades e necessidades do cotidiano profissão. Decorre daí a crítica de Girotto (2017), ao mencionar que os entraves formativos, tanto na formação do professor quanto na mediação que este exerce em sala de aula, decorre de uma lógica aplicacionista que se diz, ou é dita, crítica, mas não fura os clichês (FERRAÇO, 2015) e muito menos forma cidadãos, como preconizam os documentos que deliberam a respeito do ensinar Geografia na educação básica.

O fato é que a Geografia pronunciada como crítica, ciência social, emancipatória, formadora de cidadãos entre outros títulos, ainda não é parte da ação cotidiana do professor, não por sua culpa, pois sua autonomia é relativa e limitada, mas por um conjunto de fatores, dentre os quais a formação tem um peso significativo, sobretudo se atentarmos para o espaço onde ela ocorre: a universidade.

Das fragilidades e incertezas destes últimos tempos até a constituição de um campo de pesquisa já consolidado nas universidade brasileiras, pouco ainda se avançou em materialidade crítico-formativa. Ou seja, muito é dito, mas nem tudo é feito. As práticas dos professores da escola continuam tendo como matriz aquelas que fazem parte de seu repertório de memórias, visitadas e revisitadas sempre que necessário e reproudizidas mecanicamente.

Mas ainda deve-se reiterar que a culpa não está na ação aplicacionista ou reprodutivista do professor, de acordo com Girotto (2017), e nem também em sua formação inicial ou continuada, mas no nascedouro das políticas formativas e de currículo que não são capazes de incluir em seus roteiros as necessidades que os professores da educação básica apresentam, pois sequer são capazes de incluí-los como produtores destes documentos norteadores (LOPES, 2006). Estas políticas são produzidas e vigoram a revelia de um estreitamento entre a realidade da sala de aula da escola e das instituições formadoras, terminando por não passarem de documentos repletos de dissimetrias entre o que realmente tem o potencial de fazer a diferença na formação e na prática dos profissionais da educação e aquilo que não tem relevância ou pode ser superado. 
Muitos são os fios soltos, muitas são as pedras de tropeço pelo caminho da formação de professores, sobretudo em Geografia. Diante dos movimentos que a tentam calar, ou seja, reformulações curriculares que excluem ou rebaixam sua relevância no rol de saberes necessários a formação dos sujeitos sociais, desde os espaços escolares, é necesário repensar como estes fios (políticas, ações, sujeitos e tendências teóricometodológicas), podem se entrecruzar, de modo a fortificar e se materializar, para além do horizonte dos documentos oficiais.

\section{DESCOISIFICAR O USO DAS TICS NA FORMAÇÃO E NAS PRÁTICAS DOS PROFESSORES DE GEOGRAFIA}

É preciso, como dito, reorientar os movimentos formativos que originam tanto as práticas formadoras de professores como as formadoras do sujeito-aluno (CORTELLA, 2014). Estas reorientações advém da descoisificação do professor, no sentido de burla a alienação imposta e intencionalmente entranhada na racionalidade que constitui os documentos oficiais que regem a formação e a práticas dos professores (SARTI, 2008).

No caso específico dos professores de Geografia, há um emaranhado de fios soltos, os quais nem todos poderiam ser descritos com precisão, dada a complexidade dos processos e a amplitude do cenário de instituições incubidas de formar estes profissionais. Sabe-se que, num panorama mais geral, conforme apontado por Girotto (2017), há uma crescente desvalorização dos saberes dos professores em detrimento da valorização de saberes engessados, saberes pertencentes a um ensino arcaico e que não pensa e reelabora a si mesmo.

Ora, o professor tem por dever e necessidade refletir suas ações e os modos de conduzir suas práticas. O plural atribuído deve-se ao fato de a prática nascer com um sentido pluralista e não unívoco e unilateral, afinal a escola é um espaço dinâmico, como a própra vida e como o cotidiano, carecendo sempre de reinvenção da prática, no sentido não de apenas uma, mas de práticas e práticas (ALARCÃO, 2001; FERRAÇO, 2015).

O uso das tecnologias da informação e comunicação (TICs) pelas ideias e mãos dos professores de Geografia são um reatrato fiel da ausência da reinvenção da prática, no sentido da confecção de práticas. Nos cursos de licenciatura em Geografia e nas formações continuadas, incluindo a continuidade da formação através do cotidiano pedagógico do professor, os alunos-professores são conduzidos a conceber as tecnologias como fim e não 
como meio, ou seja, algo a ser executado e não algo a ser implantando desde o planejamento das práticas até o momento em que estas são tecidas no chão da sala de aula.

Deste modo, a ocorrência do improviso é um grave sinal de alerta. O improviso gera o impasse, pois estão atrelados de forma a constituir a problemática central quanto ao papel e uso das TICs no ensinar Geografia. Na formação recebida e na prática executada, os professores são levados a reprodução de um repertório de saberes engassados que não dialogam com as especificadades do contexto em que estarão inseridos, ou seja, da sala de aula em que trabalharão, após egresoss dos cursos de formação inicial.

A operacionalização da prática docente em Geografia (LIRA, 2014) centra a figura do professor como agente principal do processo de geração de conhecimentos sobre as temáticas. Se é que há um processo, pois nem sempre fica claro uma fluência dinâmica de atividades, muito pelo contrário, há um conjunto fragmentado de ações pontuais e descontínuas, que formam um mosaico desconexo. Assim é também na formação inicial (LEITE, 2011). As práticas formativas apresentam-se soltas, fios soltos que não dispõem de ligações entre si, não permitindo suas conexões tanto com a necessidade do campo, a formação docente, quanto com a necessidade do contexto, a sala de aula.

O professor operário é o produto desta negação ao dinamismo pedagógico. Este sujeito sente-se imbuído do poder de levar os alunos a conhecerem o que desconhecem. Verdadeiras tábulas rasas, sem qualquer saber que lhes permita associar o conhecimento em sala de aula com o cotidiano. Ferraço (2015), provocando um debate sobre a educação clichê, nos leva a descortinar os vícios de silenciamento do cotiano e do outro no processo de aprendizagem. Estes silenciamentos decorrem de um risco que o professor operário não quer correr: o imprevisível.

A aula é imprevisível. É resultante de fatores externos e internos ao momento, e nem ela mesma pode estar centrada num momento. Deve ser um contínuo momento que perdura até o próximo momento. Ou seja, aprender é uma sucessão de momentos contínuos que não necesariamente se sobrepõem ou se equivalem, mas correspondem uns aos outros, na medida em que surgem as necessidades formativas originárias do sujeitos que estão ali envolvidos.

O papel e uso das TICs é operacional e, portanto, está ligado ao utilitarismo do professor operário, que tende a nomea-las de ferramentas. A ausência de um pensar sobre e a partir das necessidades que emanam da sala de aula, levam a uma igual ausência de refletir os caminhos da formação dos alunos e de que ensino de Geografia, no caso do 
processo de ensino-aprendizagem geográfico, é desejável construir para que haja uma formação cidadã (LACHE, 2012).

O utilitarismo engessa a prática e torna as TICs algo cômodo, superficial, e, de certo modo, dispensável, pois podem ser substituidas por quaisquer outras ferramentas utilitárias, que componham a memória pedagógica do professor operário. Deste modo, o utilitarismo atribuído aos recursos tecnologicos e informacionais no ensinar Geografia tende a funcionar como "cano de escape", ao invés de mecanismo de permissividade e abertura ao campo reflexivo, que torna possível a reinvenção da prática, gerando práticas não fixadas e permitindo ao professor criar seu próprio repertório de memórias pedagógicas.

Quando enxergadas como mecanismos de mediação de aprendizagem, as TICs atingem um sentido e significado inventivo, permitindo que não sejam simplismente utilizadas por serem tecnologias e pelo apregoado discurso da necessidade de adaptação da educação aos tempos modernos, como frisa Cortella (2014), mas possibilita ajustar o foco, desfixar os sentidos e criar significados outros para as práticas de ensino.

O professor reflexivo (NÓVOA, 2002) aprende consigo mesmo que o processo de pensar suas práticas e adquirir as memórias que lhe permitam criar seus próprios mecanismos de mediação e roteiros, lhe oferece a habilidade de dar profundidade ao trato das temáticas, tematizando, até mesmo, a própria tecnologia no campo da formação dos sujeitos-alunos e no campo de sua própria formação.

A presença das TICs na aprendizagem geográfica é indispensável, uma vez que vivemos em tempos mediados pela descoberta cotidiana de recursos informacionais e tecnológicos que tornam possível formas outras de conhecer o mundo, conhecer o outro e desenvolver sociabilidades (CASTELLS, 2005). De igual maneira, a alfabetização tecnológica do professor de Geografia não pode manter distância das urgências sociais, que emanam das sociabilidades emergentes deste atual cenário, no qual as tecnologias atuam como propulsoras de variadas formas de descoberta da sociedade-mundo (SAMPAIO; LEITE, 2005).

A Geografia ensinada e vivida precisa encontrar seu espaço junto aos meios tecnológicos comunicacionais destes tempos, mas não como suporte ou âncora de uma prática que não invoque sentido e significado ao papel e uso, mas permita com que o teor da aprendizagem almejada seja fruto de uma ação reflexiva, cujo objetivo seja atingir uma 
incorporação consciente, a qual conflua de acordo com as necessidades do processo dinâmico que é o aprender.

Paralelo a isto, a formação de professores carece de lançar olhares mais aprofundados sobre a questão das TICs. Não significando isto que a formação inicial deva dar conta de toda uma gama de saberes, os quais só serão descortinados na práticia cotidiana, mas que ela oferaça aos alunos-professores uma experiência notadamente capacitativa para que estes possam munir-se de elementos reflexivos condutores de um processo de forja de práticas, as quais tenham um potencial de diálogo com as necessidades do processo educativo geográfico contemporâneo.

Fios soltos e possibilidades de uni-los: algumas inquietações conclusivas

Desde os espaços de construção e fundamentação de sua formação até a prática cotidiana em sala de aula, o professor necessita encontrar o elo entre os fios soltos e as possibilidades múltiplas de uní-los que existem na elaboração do repertório de memórias e na fuga ao estereótipo de profesor operário.

$\mathrm{O}$ aprender, na contemporaneidade, urge por outras formas de acontecimento. $\mathrm{O}$ acontecimento da aprendizagem requer mais que o estar, de acordo com Dellors (2001, p. 101), requer o "aprender a conhecer, aprender a ser, aprender a conviver e aprender a fazer". No entanto, o aprendizado que emerge da sociedade do conhecimento (LIBÂNEO, 2001) deve estar balizado por formas de conceber o próprio aprendizado como mecanismo, ou seja, não que ele seja finalidade para alguma coisa, mas que figure como processo de abertura para ampliação de saberes, que já convivem com a realidade dos sujeitos-alunos, em direção a uma cidadania que virá a ser parte de quem são estes sujeitos, como argumenta Pimenta (1999, p. 23).

\footnotetext{
A finalidade da educação escolar na sociedade tecnológica, multimídia e globalizadora é possibilitar que os alunos trabalhem os conhecimentos científicos e tecnológicos, desenvolvendo habilidades para operá-los, revê-los e reconstruí-los com sabedoria. O que implica analisá-los, confrontá-los, contextualizá-los. Para isso, há que os articular em totalidades que permitam aos alunos irem construindo a noção de "cidadania mundial".
}

Reatar os fios soltos é uma necesidade contemporânea, superando a fragilização da atividade docente e a precarização do cotidiano pedagógico, que ocorre devido a processos 
formativos rotacionais, ou seja, que se repetem sem sair do lugar comum. O professor deve ser aludido de que ele próprio pode exercer, através do processo crítico-reflexivo de revisitação das memórias pedagógicas, a construtividade de práticas que estejam de acordo com o contexto em que está inserido e com as demandas que emergerm nos cenários em que atua.

A precariedade da formação tecnológica do professor de Geografia precisa ser reduzida de modo que autorize estes sujeitos a formular uma capacidade autônoma de pensar o que pretendem e querem realizar em sala de aula. Os saberes tecnológicos não podem ser fixados a partir de modelos prontos, mas incentivados a surgirem por processo medidático reflexivo e gestão de conhecimentos, norteando a autonomia docente e a mobilização de criatividades, inventividades e busca de uma profissionalidade movida por uma racionalidade reflexiva (THERRIEN, 2002).

A tecnologia não vem em detrimento do papel do professor, como pensado por alguns, mas adentra a escola para agir em favor da ressignificação da prática e da construção de uma formação continuada que revisita os saberes tecnológicos, obtidos na formação inicial, e os impulsiona em direção a um processo de movimento dinâmico. A formação cidadã, objtivada pela escola (BRZEZINSK, 2001), acontece a partir de outras roldanas, trocadas para favorecer um real formação condutora de mentalidades que existam para pensar, e não para reproduzir.

De igual modo, a tecnologia conduz também a ressignificação do trabalho docente, produzindo saberes específicos, de acordo com Tardif (2002), que o chão da sala de aula fazem possíveis e atingíveis. Por isto, é necessário que a continuidade da formação do profesor seja encorajada desde a formação inicial, elaborando uma continuidade do caminho prático-formativo que o professor inicia nos estágios curriculares supervisionados, como sugere Pimenta (1999), e aperfeiçoa ao longo do cotidiano da profissão.

Os elos entre os fios soltos e as possibilidades de união estão atreladas a emersão de um paradigma que urge por mudanças educacionais na escola, na ação do professor, que tem tido seu trabalho constantemente julgado pela sociedade do conhecimento, e na formação inicial-continuada dos formadores (BEHRENS, 2005). O professor pode conduzir a si prórpio à reelaboração das práticas que compõem seu repertório, elaborando, junto aos seus alunos, um arcbouço de práticas que funcionam como nascedouro de outras práticas. Ou seja, estas práticas confeccionadas colaborativamente entre todos os sujeitos 
envolvidos no processo de aprendizagem não se fixam e se prendem ao professor, levandoas para onde este for, mas sejam cotidianamente aperfeiçoadas, na medida em que a aprendizagem do trabalho docente e a formação dos sujeitos-alunos se deparam com necessidades processuais.

Deste modo, o professor de Geografia precisa buscar ensinar com a Geografia (COUTO, 2010) a lidar com sociabilidades emergentes na sociedade do conhecimento, a partir dos meios tecnológico-informacionais disponíveis na contemporaneidade. E isto lhe permite pensar o espaço, a cidadania, a sociedade e o mundo a partir de outras lógicas que forneçam subsídios a formulação de problematizações sobre as temáticas que estão no circuito da sociedade-mundo.

A Geografia escolar contemporânea deve caminhar no sentido da produção de saberes sobre um mundo que se encontra em outras coordenadas formativas, ou seja, saberes necessários a educação do futuro que já s efaz presente (GADOTTI, 2000; MORIN, 2000). É preciso ponderar uma Geografia escolar de nossos tempos, uma educação geográfica que caminhe no sentido das demandas de uma soceidade-mundo que caminha rumo a uma racionalidade comunicativa, reflexiva e colaborativa.

As TICs são mecanismos de aprendizagem que favorecem a construção de conhecimentos e a produção sobre sentidos e significados que promovam aprendizagens dinâmicas e inseridas no movimento da própria vida, ou seja, o estreitamento entre Geografia e cotidiano deve estar pautado pelos elos entre o que a escola resiste em aderir, de forma mais espontânea e aberta, e o que a formação de professores negligencia.

O fomento a este trato reflexivo, na formação e na prática do professor de Geografia, possibilita a tradução de esquemas e sistemas de pensamento em ações reflexivamente tratadas como possibilidades de nortear uma formação cidadã contemporânea. E isto confere a educação geográfica a capacidade de situar-se nas coordenadas dos tempos atuais, movida por uma racionalidade outra e problematizando e tematizando a sociedade-mundo, em detrimento do aprender a sociedade e o mundo.

Superar dicotomias e diferenciações, esquizofrenias persistentes na formação de professores de Geografia, é o caminho que torna possível inserir reflexivamente as TICs na prática pedagógica cotidiana na Geografia escolar. É preciso construir relações, diálogos, metodologias colaborativas para que se caminhe no sentido de uma emancipação na formação e na prática pedagógica do professor de Geografia. Oferencendo, deste modo, a 
oportunidade com que este sujeito formador mergulher na complexidade de seu trabalho, negando a linearidade e a reprodução como formas de pensar-agir. É preciso e é possível.

\section{REFERÊNCIAS}

ALARCÃO, I. A escola reflexiva. In: ALARCÃO, I. (org). Escola reflexiva e nova racionalidade. Porto Alegre: Artmed Editora, 2001.

BEHRENS, M. A. Paradigma emergente e a prática pedagógica. Petrópolis: Vozes, 2005.

BRZEZINSKI, I. Fundamentos sociológicos, funções sociais e políticas da escola reflexiva e emancipadora: algumas aproximações. In: ALARCÃO, I. (org). Escola reflexiva e nova racionalidade. Porto Alegre: Artmed Editora, 2001.

CASTELLS, Manuel. A Sociedade em rede. Vol. I. $8^{a}$ ed. São Paulo: Paz e Terra, 2005.

CORTELlA, M. S. Educação, escola e docência: novos tempos, novas atitudes. São Paulo: Cortez, 2014.

COUTO, M. A. C. Ensinar a Geografia ou ensinar com a Geografia? Das práticas e dos saberes espaciais à construção do conhecimento geográfico na escola. Terra Livre, São Paulo, ano 26, v. 1, n 34, p. 109-224, 2010.

DAVID, C. M. Política educacional brasileira e sua dimensão social: verso e reverso. In: DAVID, C. M. (org.). Desafios contemporâneos da educação. 1. ed. São Paulo: Cutura Acadêmica, 2015.

DELLORS, J. Tesouro a descobrir. São Paulo: Cortez, 2001.

FERRAÇO, Carlos Eduardo. Educação-clichê e a necessidade de rasgar sombrinhas... ou sobre violências cotidianas e a necessidade de furar os clichês... In: GARCIA, Regina Leite; ESTEBAN, Maria Teresa; SERPA, Andréa. (Org.) Saberes cotidianos. Petrópolis: Editora De Petrus, FAPERJ, 2015.

GADOTTI, M. Perspectivas atuais da educação. São Paulo em Perspectiva, v. 14, n. 2, 2000.

GAUTHIER, C. et al. Por uma teoria da Pedagogia. Ijuí: Unijuí, 1998. 480p.

GIROTTO, E. D. Reconhecer os professores e seus saberes: ação política na formação docente em Geografa. Revista de Geografia (Recife), v. 34, n. 1, 2017, p. 91-109.

LACHE, N. M. Pensar o espaço critica e socialmente. Uma possibilidade de educação geográfica na escola. In: CASTELLAR, S. M. V.; CAVALCANTI, L. S.; CALLAI, H. C. (orgs.). Didática da Geografia: aportes teóricos e metodológicos. São Paulo: Xamã. 2012, p. 111-130. 
LEITE, Y. U. F. O lugar das práticas pedagógicas na formação inicial de professores. São Paulo: Cultura Acadêmica, 2011.

LIBÂNEO, J. C. Pedagogia e pedagogos: inquietações e buscas. Educar, Curitiba, n. 17, p. 153-176, 2001.

LIRA, S. M. O ensino de Geografia, a construção do conhecimento geográfico e a operacionalização da prática docente. In: FARIAS, P. S. C.; OLIVEIRA, M. M. (orgs.). A formação docente em Geografia: teorias e práticas. Campina Grande: EDUFCG, 2014, p. 299-320.

LOPES, A. Discursos nas políticas de currículo. Currículo sem Fronteiras, v. 6, n. 2, 2006, p. 33-52.

MORIN, E. Sete saberes necessários à educação do futuro. Trad. Catarina E. da Silva e Jeanne Sawaya. 2. ed. São Paulo: Cortez, 2000.

NÓVOA, A. Formação de professores e trabalho docente. Lisboa: EDUCA, 2002.

PEREIRA, D. A dimensão pedagógica na formação do geógrafo. Terra Livre, São Paulo, n. 14, p. 41-50, jan./jul., 1999.

PIMENTA, S. G. Formação de professores: identidade e saberes da docência. In: PIMENTA, S. G. (Org). Saberes pedagógicos e atividade docente. São Paulo: Cortez Editora, 1999, p. 15-34.

SAMPAIO, M. N.; LEITE, L. S. Alfabetização tecnológica do professor. 5. ed. Petrópolis: Vozes, 2005.

SARTI, F. M. O professor e as mil maneiras de fazer no cotidiano escolar. EDUCAÇÃO: teoria e prática, v. 18, n. 30, jan-jun de 2008, p. 47-65.

SCHÖN, D. Formar professores como profissionais reflexivos. In: NÓVOA, A. (Coord.). Os Professores e a sua Formação. 3ª ed. Lisboa: Publicações Dom Qu1ixote, 1997.

SILVA, T. E. O professor e o comate à alienação imposta. 6. ed. São Paulo: Cortez, 2011.

TARDIF, M. Saberes docentes e formação profissional. 2. ed. Petrópolis: Vozes, 2002

THERRIEN, J. O saber do trabalho docente e a formação do professor. In: NETO, A. S.; MACIEL, L. S. B. (orgs.). Reflexões sobre a formação de professores. Campinas: Papirus. 2002.

1-70, jan/abr. 2002. 